\title{
Efficacy and Safety of Carbetocin in Comparison to Oxytocin for the Prevention of Primary PPH during Caesarean Section: An Open Label Randomized Control Trial
}

\author{
N KABIR ${ }^{\mathrm{a}}$, BH ARA $^{\mathrm{b}}$, D AKTER $^{\mathrm{c}}$, TA DAISY $^{\mathrm{d}}, \mathrm{S} \mathrm{JESMIN}^{\mathrm{e}}$, M RAZZAK $^{\mathrm{f}}$, H BEGUM $^{\mathrm{g}}$, GMR ISLAM $^{\mathrm{h}}$
}

Summary:

Background: Postpartum hemorrhage (PPH) is a potentially life-threatening complication of both vaginal and caesarean delivery. The most frequent cause of postpartum hemorrhage is uterine atony, when the uterus fails to contract fully after delivery of the placenta. For the prevention of this uterine atony we need an effective uterotonic drug. Till now oxytocin is used for enhancing uterine contraction after delivery. But oxytocin has some limitations like shorter halflife, less contraction time and more side effects, whereas carbetocin has prolonged duration of action which ensures more contraction time and less adverse effects. So, carbetocin considered as a good alternative over oxytocin for the prevention of primary PPH in caesarean section.

The Aim of Study: To see the efficacy and safety of carbetocin over oxytocin for the prevention of primary $\mathrm{PPH}$ during caesarean section.

Patients and Methods: A randomized-controlled trial was conducted in the Institute of Child and Mother Health (ICMH), Dhaka, Bangladesh over a period of nine months from January to September 2016. Ninety-four patients who had got admitted in ICMH undergoing caesarean section at term were randomized into two groups receiving either $10 I U$ oxytocin or $100 \mu g$ carbetocin, after the operation.

a. Prof. Nazneen Kabir, Ex. Executive Director \& Head of Obstetrics and Gynecology, Institute of Child and Mother Health (ICMH), Matuail, Dhaka.

b. Prof. Dr. Begum Hosne Ara, Executive Director \& Head of Obstetrics and Gynecology, Institute of Child and Mother Health (ICMH), Matuail, Dhaka.

c. Dr. Dilruba Akter, Professor, Department of Obstetrics and Gynecology, ICMH, Matuail, Dhaka.

d. Dr. Tahmina Afrin Daisy, Associate Professor, Dept. of Obstetrics and Gynecology ICMH, Matuail, Dhaka.

e. Dr. Sonia Jesmin, Assistant Professor, Department of Obstetrics and Gynecology, ICMH, Matuail, Dhaka.

f. Dr. Mollika Razzak, Assistant Professor, Department of Obstetrics and Gynecology, ICMH, Matuail, Dhaka.

g. Dr. Hasina Begum, Assistant Professor, Department of Obstetrics and Gynecology, ICMH, Matuail, Dhaka.

h. Dr. G. M. Raihanul Islam, Senior Manager, MSD, Beacon Pharmaceuticals Ltd.

Address of Correspondence: Prof. Nazneen Kabir, Ex. Executive Director \& Head of Obstetrics and Gynecology, Institute of Child and Mother Health (ICMH), Matuail, Dhaka. Mobile: 01711563876 , E-mail : edrafed@gmail.com

Received: 14 December 2017

Accepted: 25 October 2018
Outcome measures such as primary PPH, massive blood loss, need for additional uterotonic drug, additional blood transfusion as well as adverse effects were all documented.

Results: This study had shown that carbetocin is superior in comparison to oxytocin for the prevention of primary PPH following caesarean section. Each patient obtained either a single dose of 100 microgram carbetocin intravenously or 10 IU of oxytocin during caesarean section. Massive blood loss occurred in 6.4\%patients, blood transfusion needed in $17 \%$ patients and additional uterotonic needed for $25.5 \%$ patients in oxytocin group but in carbetocin group no massive blood loss occurred, only $2.1 \%$ patient needed immediate blood transfusion and no patient was required additional uterotonics. There were no major adverse effects observed in both the groups. No patients had developed PPH in carbetocin group. But $12.8 \%$ patients had developed primary PPH in oxytocin group.

Conclusion: Carbetocin appears to be an effective new drug than oxytocin for the prevention of primary postpartum hemorrhage in caesarean section.

Key Words: Carbetocin, Oxytocin, Postpartum hemorrhage.

(J Bangladesh Coll Phys Surg 2019; 37: 19-24)

DOI: http://dx.doi.org/10.3329/jbcps.v37i1.39285

Introduction:

Postpartum Hemorrhage (PPH) is a potentially lifethreatening complication of both vaginal and cesarean delivery. PPH complicates $11 \%$ of deliveries worldwide, and is annually responsible for 1, 32, 000 maternal deaths ${ }^{1}$. In developing countries, mortality from PPH remains high ${ }^{2}$. In low income setting, PPH accounting for $30 \%$ of maternal death ${ }^{3}$, while in Bangladesh it is $31 \%{ }^{4}$. The target of MDG-2015 was 143 deaths per 100,000 live births ${ }^{5,6}$. We have already achieved this target. The key contribution to this decrease was a drop-in mortality risk mainly due to improved access and use of health facilities. Now, building on the momentum generated by MDG-5, the sustainable development goals (SDGs) establish a transformative new agenda for maternal health towards ending preventable maternal mortality. Target of SDG 
3 is to reduce the global maternal mortality ratio to less than 70 per 100000 live births by $2030^{7}$.

Use of an effective uterotonic drug for prevention of uterine atony as well as PPH is highly recommended. Primary PPH is the most common obstetric hemorrhage and is defined by theWorld Health Organization as the loss of blood estimated to be $>1000 \mathrm{ml}$ from the genital tract after caesarean section within 24 hours of delivery ${ }^{8}$.

Primary PPH is the most common one and up to $80 \%$ cases it occurs due to uterine atony ${ }^{5}$, when the uterus fails to contract fully after delivery of the placenta. There are numerous reasons for the uterus failing to contract effectively; including exhaustion, sepsis etc. Other causes of $\mathrm{PPH}$ are suspected or proven placental abruption, known placenta previa, multiple pregnancy, preeclampsia, gestational hypertension, previous $\mathrm{PPH}$, Asian ethnicity, obesity (BMI $>35)$ and anaemia $(<9 \mathrm{~g} /$ dl). Intrapartum risks include: Delivery by emergency or elective caesarean section, induction of labour, retained placenta, mediolateral episiotomy, operative vaginal delivery, prolonged labour ( $>12$ hours), big baby ( $>4 \mathrm{~kg}$ ), pyrexia in labour, and age $>40$ years ${ }^{9}$.

If obstetric hemorrhage is not managed efficiently and effectively, this will lead to shock, hemostatic failure from disseminated intravascular coagulation, and ultimately death ${ }^{10}$.

Conventional uterotonics like oxytocin has used for preventing PPH but it has some limitations like shorter half- life ${ }^{11}$, less contraction time and more side effects like fluid overload, convulsion, arrhythmia and pulmonary edema. In addition, the ergot alkaloids cannot be used in $10-15 \%$ of women who have gestational hypertension ${ }^{12}$. Further, oxytocin and ergot preparation require protection against light to preserve its effectiveness and stability ${ }^{13}$. In our country cold chain is not properly maintained for oxytocin. So, there is a chance of its effectiveness and stability problems. As a result, treatment failure may occur, bleeding due to uterine atony, can be prevented by an effective uterotonic agent ${ }^{14}$. Till now it is recommended that oxytocin should be used as uterotonic agent either in the form of intramuscular injection or intravenous infusion.

Carbetocin is a long-acting synthetic analogue of oxytocin with agonist properties ${ }^{15,16}$. Carbetocin has prolonged duration of action (approximately 1 hour) which ensures more contraction time and less adverse effect ${ }^{17,18}$. The clinical and pharmacological properties of carbetocin are similar to those of naturally occurring oxytocin. Carbetocin binds to oxytocin receptors present on the smooth musculature of the uterus, resulting in rhythmic contractions of the uterus, increased frequency of existing contractions and increased uterine tone ${ }^{13}$. A single dose of carbetocin has been hypothesis to act up to 16 hours in comparison to intravenous oxytocin infusion regarding the increase in uterine tone and the reduction of the risk of PPH in caesarean section ${ }^{12}$.Moreover, carbetocin ensures more effective contraction and less adverse effect like headache, tremor, hypotension, nausea, abdominal pain, and pruritus ${ }^{13}$.Several data of literature suggest that prophylactic administration of carbetocin may be a good alternative to oxytocin to prevent post-partum hemorrhage ${ }^{19}$. We had conducted this clinical study to evaluate the efficacy and safety of Carbetocin for the prevention of primary PPH during caesarean section.Materials and Methods

This randomized control trial was done from January'2016 to Septembar'2016 in the Department of Obstetrics and Gynecology, Institute of Child and Mother Health (ICMH), Matuail, Dhaka, Bangladesh. About ninety-four pregnant women were included in this study. The participants were enrolled in the study after fulfilling the inclusion and exclusion criteria. According to computer generated randomization sequential number was allocated for the cases. A written informed consent was taken from eligible women on admission. The study protocol was approved by the ethical committee of Institute of Child and Mother Health (ICMH), Matuail, Dhaka, Bangladesh.

Inclusion criteria were women with a single pregnancy undergoing caesarean delivery above 36 weeks or greater (gestational age was recorded according to the last menstrual period and was confirmed by ultrasound report).Exclusion criteria were placenta previa, multiple gestation, placental abruption (determined by history and ultrasound report) hypertensive disorders in pregnancy, preeclampsia, and known case of cardiac, renal, liver diseases, epilepsy, moderate anemia and unwilling to participate in the study.

During the study period 47 women were enrolled who received Carbetocin100 1/4g I/V as a single dose and 
47 women who received 10 IU of oxytocin after caesarean section. The primary outcome was measured by the amount of blood loss within 24 hours after delivery. Blood loss was estimated by the surgeon in the usual way (visual estimation, number of used sanitary pad and amount of aspirated blood. The secondary outcomes were massive blood loss, need for additional uterotonic drug, additional blood transfusion as well as adverse effects within 24 hours of delivery. Uterine tone was evaluated by palpation and administration of additional uterotonics was the decision of the investigator.

Analysis was performed by using a computer based statistical program SPSS (Statistical Package for Social Sciences) version 16. Quantitative data were expressed as means \pm SD. $95 \%$ confidenceinterval was calculated and $\mathrm{p}$ value of $<0.05$ was considered as significance.

\section{Result:}

A total of 105 pregnant women with a single pregnancy were initially recruited for inclusion in this study. 11 cases were excluded ( 4 had pre-eclampsia, 2 eclampsia, 3 multiple gestation, 2 severely anaemic). Thus 94 women formed the final study group and were included in the final analysis. Mean age of study population were $23.7 \pm 3.7$ in carbetocin group and $24.7 \pm 4.3$ in oxytocin group(Table I). Among the study patients $38.3 \%$ (18) had mild anemia in Carbetocin group and $40.4 \%$ (19) had mild anemia in oxytocin group. Mean systolic BP of women were $108 \pm 8.6 \mathrm{~mm}$ of $\mathrm{Hg}$ and Diastolic BP were $71 \pm 5.4 \mathrm{~mm}$ of $\mathrm{Hg}$ in Carbetocin group and mean systolic BP were 105 \pm 7.2 $\mathrm{mm}$ of $\mathrm{Hg}$ and Diastolic BP were $70 \pm 6.2 \mathrm{~mm}$ of $\mathrm{Hg}$ in Oxytocin group. Mean gestational age at delivery were $38.8 \pm 1.3$ in Carbetocin group and $39 \pm 1.5$ in Oxytocin group (Table-1). Massive blood loss occurred in $6.4 \%$ cases, blood transfusion needed in $17 \%$ cases and additional uterotonic drug needed for $25.5 \%$ women in oxytocin group but in carbetocin group no massive blood loss, only $2.1 \%$ needed immediate blood transfusion and no patient was required additional uterotonics (Table-2). There were no major adverse effects observed in both the groups (Table-3). No patients had developed PPH in carbetocin group. But $12.8 \%$ (6) patients had developed PPH in oxytocin group (Table-4).

Table-1. Data are presented as mean $\pm \mathrm{SD}$. The mean differences were not statistically significant $(\mathrm{P}>0.05)$

Table-2. Shows that massive blood loss occurred in $6.4 \%$ patients, blood transfusion needed for $17 \%$ patients and additional uterotonic drug needed for 25.5\% patients in Oxytocin group but in carbetocin

Table-I

\begin{tabular}{lccc}
\multicolumn{4}{c}{ Baseline characteristics of study patients $(n=94)$} \\
& Carbetocin Group $(\mathrm{n}=47)$ & Oxytocin Group $(\mathrm{n}=47)$ & P value \\
\hline Age & $23.7 \pm 3.7$ & $24.7 \pm 4.3$ & 0.317 \\
Mild Anemia & $18(38.3 \%)$ & $19(40.4 \%)$ & 0.317 \\
Systolic BP & $108 \pm 8.6 \mathrm{~mm}$ of $\mathrm{Hg}$ & $105 \pm 7.2$ & 0.210 \\
Diastolic BP & $71 \pm 5.4 \mathrm{~mm}$ of $\mathrm{Hg}$ & $70 \pm 6.2 \mathrm{~mm}$ of Hg & 0.509 \\
Gestational Age & $38.8 \pm 1.3$ weeks & $39 \pm 1.5$ weeks & 0.799 \\
\hline
\end{tabular}

Table-II

\begin{tabular}{lccccc}
\multicolumn{5}{c}{ Outcome of Third stage of Labour $(n=94)$} & \\
Outcome of 3rd stage of Labour & Carbetocin & Group (n=47) & Oxytocin & Group(n=47) & P value \\
\hline & Yes (\%) & No (\%) & Yes (\%) & No (\%) & \\
Massive blood loss & $0(0 \%)$ & $47(100 \%)$ & $3(6.4 \%)$ & $44(93.6 \%)$ & 0.001 \\
Blood transfusion & $1(2.1 \%)$ & $46(97.9 \%)$ & $8(17 \%)$ & $39(83 \%)$ & 0.001 \\
Need for additional uterotonics & $0(0 \%)$ & $47(100 \%)$ & $12(25.5 \%)$ & $35(74.5 \%)$ & 0.001 \\
\hline
\end{tabular}


group no massive blood loss occurred and blood transfusion needed only $2.1 \%$ patient and none of patient was required additional uterotonics. The mean differences were statistically significant $(\mathrm{P}<0.05)$.

Table-3. There were no major adverse effects observed in both groups. The differences were not statistically significant $(\mathrm{P}>0.05)$.

Table- 4. Showed no patients had developed PPH in carbetocin group. But $12.8 \%$ patients had developed $\mathrm{PPH}$ in oxytocin group. The mean differences were statistically significant $(\mathrm{P}<0.05)$.

\section{Table-III}

\begin{tabular}{lccc}
\multicolumn{4}{c}{ Adverse effects $(n=94)$} \\
\multicolumn{1}{c}{ Side effects } & $\begin{array}{c}\text { Carbetocin } \\
(\mathrm{n}=47)\end{array}$ & $\begin{array}{c}\text { Oxytocin } \\
(\mathrm{n}=47))\end{array}$ & P value \\
& $\mathrm{n}(\%$ & $\mathrm{n}(\%)$ & \\
\hline Nausea & $(1) 2.1 \%$ & $1(2.1 \%)$ & 0.50 \\
Vomiting & $1(2.1 \%)$ & $0(0 \%)$ & 0.30 \\
Fever & $0(0 \%)$ & $0(0 \%)$ & 0.50 \\
Arrhythmia & $0(0 \%)$ & $0(0 \%)$ & 0.50 \\
Pulmonary edema & $0(0 \%)$ & $0(0 \%)$ & 0.50 \\
Abdominal Pain & $4(8.5 \%)$ & $5(10.6 \%)$ & 0.72 \\
Headache & $0(0 \%)$ & $1(2.1 \%)$ & 0.30 \\
Tremor & $0(0 \%)$ & $0(0 \%)$ & 0.50 \\
Hypotension & $0(0 \%)$ & $0(0 \%)$ & 0.50 \\
Pruritus & $0(0 \%)$ & $0(0 \%)$ & 0.50
\end{tabular}

Table-IV

Outcome of the patient: Primary PPH $(n=94)$
\begin{tabular}{lccc} 
Outcome & Carbetocin & Oxytocin & P Value \\
\hline ( Primary PPH) & group (47) & group (47) & \\
Yes & $0(0 \%)$ & $6(12.8 \%)$ & 0.001 \\
No & $47(100 \%)$ & $41(87.2 \%)$ & \\
\hline
\end{tabular}

\section{Discussion:}

In the present study each patient obtained a single dose of 100 microgram carbetocin intravenously during cesarean section, immediately after the delivery of the baby and prior to the delivery of the placenta. Outcome measures such as primary PPH, massive blood loss, need for additional uterotonic drug, additional blood transfusion as well as adverse effects were documented.
Reyes OA and Gonzalez GM et al showed that mean age of study patient in carbetocin group were 26.5 years and 26.7 years in oxytocin group ${ }^{20}$. In this study mean age of study patients were 23.7 years in carbetocin group and 24.7 years in oxytocin group.A study from Philippine found that mean preoperative systolic BP of study patients in carbetocin group were $117 \pm 6.8$ $\mathrm{mm}$ of $\mathrm{Hg}$ and diastolic BP were $69 \pm 7.7 \mathrm{~mm}$ of $\mathrm{Hg}$ and mean preoperative systolic BP were $118 \pm 8.3 \mathrm{~mm}$ of $\mathrm{Hg}$ and diastolic BP were $73 \pm 8.5 \mathrm{~mm}$ of $\mathrm{Hg}$ in Oxytocin group ${ }^{21}$. In this study, mean preoperative systolic BP of patients were $108 \pm 8.6 \mathrm{~mm}$ of $\mathrm{Hg}$ and diastolic BP were $71 \pm 5.4 \mathrm{~mm}$ of $\mathrm{Hg}$ in carbetocin group and mean systolic BP were $105 \pm 7.2 \mathrm{~mm}$ of $\mathrm{Hg}$ and diastolic BP were $70 \pm 6.2 \mathrm{~mm}$ of $\mathrm{Hg}$ in oxytocin group which were almost similar with previous study.All patients of both the groups were with normal blood pressure.

A study in Panama showed that the mean gestational age of study women in carbetocin group were 37.44 weeks and 36.93 weeks in oxytocin group ${ }^{20}$ which is almost similar to this study; $38.8 \pm 1.3$ weeks weeks in carbetocin group and $39 \pm 1.5$ weeks weeks in oxytocin group. They also showed that there was no significant difference between the two study groups regarding occurrence of adverse effects of both the drugs. In present study, there were no major adverse effects observed in both the groups.

In this study, only $2.1 \%(1)$ patient in carbetocin group was needed blood transfusion but in oxytocin group blood transfusion were required for $17 \%(8)$ patients which was almost similar to a previous study. ${ }^{22}$

Current study showed that, none of patients of carbetocin group were required additional uterotonics but in oxytocin group additional uterotonics were required for $25.5 \%$ patients. Similar results were also found in previous study. ${ }^{21,22,23}$

Occurrence of PPH were less in carbetocin group of this study. This result was similar to a previous prospective double-blinded randomized study conducted in Egypt. ${ }^{25}$

Primary postpartum hemorrhage (PPH) is the most common form of major obstetric hemorrhage ${ }^{26}$. It is the most common cause of maternal morbidity in developed countries and a major cause of death worldwide ${ }^{27,28}$. The most common point at which PPH 
occurs is during the third stage of labour, when the uterus may suddenly loss its ability to contract. Around $80 \%$ of cases of postpartum hemorrhage occur due to uterine atony ${ }^{29}$. Bleeding due to uterine atony, can be prevented by an effective uterotonic drug ${ }^{30}$. The promising findings suggested that carbetocin appears to be an effective new drug for the prevention of $\mathrm{PPH}$ in caesarian delivery. A single dose of 100 microgram IV carbetocin is more effective than oxytocin for maintaining adequate uterine tone, decreases blood loss and preventing postpartum hemorrhage in women undergoing caesarian delivery. Carbetocin can be considered as a good uterotonic agent over oxytocin for the prevention of primary $\mathrm{PPH}$ in caesarian section.

\section{Acknowledgments:}

The research team would like to thank all doctors, health staff and patients for participating in the clinical trial.Special thanks to Beacon Pharmaceuticals Limited, Bangladesh for free supply of Duratocin.

\section{Conflict of interest}

The authors declare that there is no conflict of interests regarding the clinical trial.

\section{References:}

1. Carroli G, Cuesta C, Abalos E and Gulmezoglu A.M. Epidemiology of postpartum haemorrhage: A systematic review. Best. Pract. Res. Clin. Obstet. Gynaecol, 2008;22 (6): 999-1012.

2. American Academy of Family Practitioners (AAFP);2008.[cited 2008 may 21] Advanced Life Support in Obstetrics.Available from www.aafp.org/online/en/ home/cme/aafpcourses/ clinicalcourses/also/syllabus. html\#Parsys0003, 2008.

3. Derman R, Kodkany BS, Goudar SS, Geller SE, Naik VA, Bellad MB, Patted SS, Patel A, Edlavitch SA, Hartwell T, Chakraborty $\mathrm{H}$, Moss N. Oral misoprostol in preventing postpartum hemorrhage in resource-poor communities: a randomised controlled trial. Lancet 2006; 368:1248-53.

4. National Institute of Population Research and Training (NIPORT). MEASURE Evaluation.UNC-CH, USA, ICDDR, $\mathrm{B} ; 2011$.

5. Bangladesh. National Institute of Population Research and Training (NIPORT).Maternal Mortality Survey;2010.

6. Bangladesh demographic and health survey;2011.

7. WHO, UNICEF, UNFPA, World Bank, and the United Nations Population Division. Trends in Maternal Mortality: 1990 to 2015.Geneva; 2015.

8. World Health Organization: WHO Guidelines for the Management of Postpartum Hemorrhage and Retained Placenta.Available from http://whqlibdoc.who.int/publications/ 2009/9789241598514_eng.pdf, 2009.
9. Royal College for Obstetricians and gynecologists. Prevention and management of postpartum hemorrhage. Green-top Guideline No. 52, 2009.

10. Briley A and Bewle S. Management of obstetric haemorrhage. In: Sue Pavrod and Beverly Hunt. The Obstetric Hematology Manual. United State of America, Cambridge University Press, ISBN-13 978-0-521-86564- 7, Section 5 Chapter 13a, 2010.

11. Oyelese Y, Scorza WE, Mastrolia R, Smulian JC.Post-partum hemorrhage. Obstet Gynecol Clin N Am. 2007; 34(3):421-441.

12. Larciprete G, MontagnoliC, FrigoM, PanettaV, Prenat J et al. Carbetocin versus oxytocin in caesarean section with high risk of post-partum hemorrhage Med. 2013 Jan-Mar; 7(1): 12-18.

13. Werner R. Prevention of postpartum hemorrhage with the oxytocin analogue carbetocin. European Journal of Obstetrics and Gynecology and Reproductive Biology, 2009; 147 (1): 1520.

14. Derman R, Kodkany BS, Goudar SS, Geller SE, Naik VA, Bellad MB, Patted SS, Patel A, Edlavitch SA, Hartwell T, Chakraborty $\mathrm{H}$, Moss N. Oral misoprostol in preventing postpartum hemorrhage in resource-poor communities: a randomized controlled trial. Lancet2006; 368:1248-53.

15. Gazi R, Quaiyum A, Islam M, Hossain S, Wirtz, AL, Saha, NC, Jesmin M. Post-Partum Excessive Bleeding among Bangladeshi Women: Determinants, Perceptions, Recognition, Responses. Centre for Equity and Health Systems, ICDDRB, Dhaka, Bangladesh. Published November 15, 2012.

16. Attilakos G, Psaroudakis D, Ash J, Buchanan R, Winter C, Donald F, Hunt L, Draycott T. Carbetocin versus oxytocin for the prevention of postpartum haemorrhage following caesarean section: the results of a double-blind randomized trial. BJOG 2010; 117:929-936.

17. Tharakan T, Jha J Randomized double blind prospective trial of active management of the third stage of labor. Arch Med Sci 2008; 4(1):79-82.

18. Sergio RO, RP Aguado et al. Carbetocin versus oxytocin for prevention of postpartum haemorrhage: a randomized controlled trial. School of Clinical and Experimental Medicine, University of Birmingham, UK. Published Online February 26, 2014.

19. Yuen MP.Oxytocic Agents for the Management of Postpartum Hemorrhage 2011; 16: 10.

20. Reyes OA, Gonzalez GM. Carbetocin versus oxytocin for prevention of postpartum hemorrhage in patients with severe preeclampsia: a double-blind randomized controlled trial. J obstet gynaecol can 2011;33(11):1099-1104.

21. Lynuy D, Atherinep $\mathrm{N}$ et al. Carbetocin versus Oxytocin for the Prevention of Postpartum Haemorrhage Following Elective Cesarean Section: Rizal Medical Center Experience; Philippine Journal of Obstetrics \& Gynecology. 2013; 37 (2):71-79.

22. Manal M, Behery EL, Abbas G, Sayeda EL, Azza A et al. Carbetocin versus oxytocin for prevention of postpartum 
hemorrhage in obese nulliparous women undergoing emergency cesarean delivery; Matern J Fetal Neonatal Med.2016; 29(8):1257.

23. Ortiz SR, Aguado RP, Hernandez RS, Castorena M et al. Carbetocin versus oxytocin for prevention of postpartum hemorrhage: a randomized controlled trial; The Lancet. 2014;383:5.

24. Holleboom CAG. Eyck JV, Koenen SV. Carbetocin in comparison with oxytocin in several dosing regimens for the prevention of uterine atony after elective caesarean section in the Netherlands. Arch Gynecol Obstet 2013; 287:1111-1117.

25. Maged AM, Gany A, Hassan A, Nesreen AA. Carbetocin versus oxytocin for prevention of postpartum hemorrhage after vaginal delivery in high risk women; J Matern Fetal Neonatal Med, 2015; 29(4): 532-536.

26. Prevention and management of postpartum haemorrhage, Royal College of Obstetricians and Gynecologists, Green-top Guideline No. 52, Minor revisions November 2009 and April 2011.
27. The Prevention and Management of Postpartum Haemorrhage: Report of Technical Working Group, Geneva 3-6 July 1989. Geneva: World Health Organization, 1990.

28. Bais JM, Eskes M, Pel M, Bonsel GJ, Bleker OP. Postpartum haemorrhage in nulliparous women: incidence and risk factors in low and high risk women. A Dutch population-based cohort study .Eur J Obstet Gynecol Reprod Biol. 2004; 115: 166-72.

29. Dutch Association of Obstetrics and Gynaecology (NVOG). Guideline postpartum hemorrhage. 2012;1-9.

30. Chandhiok N, Dhillon BS, Datey S, Mathur A, Saxena NC. Oral misoprostol for prevention of postpartum haemorrhage by paramedical workers in India. Int J Gynaecol Obstet 2006; 92:170-75.

31. Sheehan SR, Montgomery AA, Carey M, et al. Oxytocin bolus versus oxytocin bolus and infusion for control of blood loss at elective caesarean section: double blind, placebo controlled, randomised trial. The BMJ. 2011 August 1;343:4661. 